\title{
Economia Política da redução do tempo de trabalho: dos autores pioneiros ao debate contemporâneo sobre transições para sustentabilidade
}

Political Economy of working time reduction: from pioneer authors to the contemporary debate on sustainability transitions

\author{
Paulo Sérgio Fracalanza(1) \\ Mariana Rêis Maria (2) \\ Rosana Icassatti Corazza ${ }^{(3)}$ \\ (1) Universidade Estadual de Campinas \\ (2) Universidade Estadual de Campinas \\ (3) Universidade Estadual de Campinas
}

\begin{abstract}
This review-paper presents, inspired by Polanyi, the working time reduction (WTR) in its substantive sense, which allows putting forward WTR proposals as vectors of socioeconomic change to a more sustainable, fairer and emancipatory system. A first section is devoted to comparing the meanings of WTR in its formal and substantive senses. The second section is devoted to the pioneering views of Keynes, Russell, and Lafargue on WTR. Finally, the third section brings together three important contemporary authors, Gorz, Jackson and Méda, who, in the sustainability transitions debate, give special attention to WTR as one of the needed changes towards the reorganization of the socioeconomic system in order to make it compatible with the biogeophysical limits of our planet.
\end{abstract}

\section{Keywords}

working time reduction, substantivism, transitions, ecological reconversion.

JEL Codes B25, B31, N30.

\section{Resumo}

Esse artigo-resenha apresenta, inspirado por Polanyi, a redução do tempo de trabalho (RTT) em seu sentido substantivo, o que permite sugerir o encaminhamento de propostas de RTT como vetores de mudança socioeconômica para um sistema mais sustentável, mais justo e com maior potencial emancipatório. Uma primeira seção é dedicada a cotejar os significados da RTT em seus sentidos formal e substantivo. A segunda seção é dedicada às visões precursoras de Keynes, Russell e Lafargue sobre a RTT. Finalmente, a terceira, reúne três importantes autores contemporâneos, Gorz, Jackson e Méda, que, no debate sobre a transição para a sustentabilidade, dão especial destaque às medidas de RTT no rol das transformações necessárias rumo à reorganização do sistema econômico e social compativel com os limites biogeofísicos de nosso planeta.

\section{Palavras-chave}

redução do tempo de trabalho, substantivismo, transições, reconversão ecológica.

Códigos JEL $B 25, B 31, N 30$. 


\section{Introdução}

A crise de 2008 e suas consequências não parecem próximas de acabar. Pouco frequente entre economistas, essa condição permitiu um diagnóstico consensual de um slowdown mundial persistente, embora as explicações para o fenômeno não encontrem a mesma unanimidade. Crises e arrefecimento do crescimento vêm historicamente acompanhados do agravamento do panorama do mundo do trabalho, convulsionado por alarmantes e persistentes níveis de desemprego de massa que atingem países desenvolvidos e em desenvolvimento. $O$ crescimento da informalidade no mercado de trabalho, do exército do precariado e da redução das taxas de participação, entre outros fenômenos correlatos, amplia as consequências negativas para os trabalhadores (ILO, 2016; Standing, 2013). A fatura torna-se ainda mais amarga pelas respostas à crise que aprofundam o desmantelamento das redes de proteção erigidas pelos Estados de Bem-Estar Social, alimentada pela crescente importância política das agremiações de extrema-direita e pela nova arquitetura das políticas neoliberais que ganham os contornos, na perspicaz acepção de Davies (2016), de um neoliberalismo punitivo. Somam-se às consequências da crise o crescimento da insegurança (real e fictícia) que alimenta disposições belicistas, enquanto se segue o drama dos refugiados, a crescente insegurança dos imigrantes e a agudização dos conflitos nas periferias das grandes cidades. Todos esses fenômenos são embalados por uma crescente consciência da ampliação das desigualdades, do fosso entre os muito ricos e a multidão de remediados e despossuídos, tanto nos anos anteriores à crise quanto depois dela (Wilkinson; Pickett, 2010; Piketty, 2013).

Como resposta às terapêuticas dominantes, acumulam-se no campo progressista os argumentos condenatórios à austeridade, à insuficiente resposta dos países, desenvolvidos e emergentes, à crise, ou, talvez melhor dizendo, à contraproducente resposta desses mesmos países, empenhados em medidas de contenção dos déficits fiscais, em reformas visando à flexibilização de direitos e na redução da abrangência das políticas de proteção social, ao mesmo tempo que se ampliam as benesses concedidas aos proprietários do capital. Essa insatisfação com as medidas tomadas tem provocado constantes choques entre as reivindicações dos trabalhadores e as respostas austeras adotadas. Na esteira da tradição neoliberal, medidas de flexibilização do mercado de trabalho emergiram como "moeda de troca" para recebimento de auxílios financeiros no sentido de estancar a crise em diversos países. 
Num outro registro, o da partilha do emprego, a redução do tempo de trabalho (RTT) ressurge como proposta, já tendo sido aposta para criação de empregos em diversos momentos da história (Fracalanza, 2008). Todavia, a RTT não se apresenta somente como alternativa para criação de empregos, mas como medida de ressignificação do modo de vida. Assim, caminha-se ao encontro do que sugerimos denominar de significado "substantivo" da RTT, que ganha novos aprofundamentos a partir de críticas ao crescimento econômico per se frente à efervescente temática ambiental. Esta impõe desafios a estudiosos e formuladores de políticas que vão muito além da promoção do crescimento e do desenvolvimento tecnológico, ao exigir que reflitamos sobre as formas de interação social que forjamos e, quiçá, com o desenho (e o desejo) de transformações da maneira como produzimos, consumimos e nos organizamos como coletividades.

Esses questionamentos, portanto, na tradição da Economia Política não são ociosos: é realmente possivel retomar o crescimento econômico? Ainda que se vislumbre a concretude dessa possibilidade, restariam outras questões. Uma retomada do crescimento seria possível em níveis que permitissem uma nova era de prosperidade global? Se sim, este seria o caminho para a superação das dificuldades antes elencadas? Seria sustentável esse novo esperado ciclo de crescimento, num cenário business as usual?

Nesse contexto, o objetivo neste artigo consiste em examinar a alternativa da redução do tempo de trabalho como uma das políticas preconizadas por um conjunto de autores contemporâneos que estudam propostas de transição da economia num contexto de destruição da resiliência dos sistemas naturais. Para isso, propomos um roteiro ordenado em três partes. Numa primeira, inspirados por Polanyi, apresentamos a proposta da RTT numa dupla perspectiva. De um lado, a ideia da RTT em seu sentido formal, da busca da eficiência econômica e limitada, portanto, às condições ditadas pela valorização do capital. De outro, apresentamos a RTT em seu sentido substantivo, ou seja, uma reabilitação dessa proposta como libertação da carga de trabalho, como emancipação da acumulação sem sentido e como condição e gatilho para transformações sociais associadas a outras ou novas maneiras de viver. Na segunda parte, abordam-se as contribuições de três precursores da RTT em seu sentido substantivo: Keynes, Russell e Lafargue. Finalmente, na terceira parte, são expostas contribuições que vislumbram na RTT uma forma de superação do modo atual de organização da produção e reprodução material e 
simbólica da vida social: as óticas do filósofo André Gorz, do economista Tim Jackson e da socióloga Dominique Méda. Ao lado de suas convergências teóricas e desacordos, a RTT aparece como um elemento fundamental para uma transição para novas formas de organização social nas quais a acumulação desenfreada de capital e o consumo movido pela ideia de ilimitadas necessidades não sejam os pilares da dinâmica sistêmica. Com isso, podem-se vislumbrar possibilidades de emancipação social com a preservação do planeta.

\section{Dois significados da redução do tempo de trabalho à la manière de Polanyi}

Polanyi, numa crítica contundente à leitura histórica do capitalismo no ideário liberal, contrapõe a acepção dominante de economia ao seu sentido "substantivo". Nos marcos da tradição dominante à la Robbins, o primeiro significado, o formal, comparece a partir do caráter lógico da relação entre fins e meios. Ali se constrói a narrativa da naturalização dos desejos ilimitados da humanidade, da escassez dos meios para prover às necessidades humanas, da forma específica da racionalidade em todos e quaisquer processos da reprodução material, do papel virtuoso dos mercados, da tendência natural à troca e dos benefícios públicos que se destilam da natureza humana egoísta, cúpida e violenta.

Em contraponto, Polanyi, orientado por sua pesquisa antropológica e histórica sobre os diferentes mecanismos de integração social - a reciprocidade, a distribuição e a troca -, propõe a recuperação do significado da economia em seu sentido substantivo. Trata-se do sentido da subsistência humana, apontando "para a realidade elementar de que os seres humanos, como quaisquer outros seres vivos, não podem existir sem um meio físico que os sustente" (Polanyi, 2012b, p. 63).

Portanto, a proposta aqui é apresentar os dois significados para a RTT, evidenciando sua estreita homologia com os significados do econômico no pensamento de Polanyi. ${ }^{1}$

Historicamente, a extensão da duração do tempo de trabalho conheceu intensas flutuações. Pode-se dividir a história da duração do trabalho em dador do substantivismo em Economia. A esse respeito, consultar Wjuniski e Fernandez (2010). 
dois períodos contrastantes. Entre os séculos XIV e meados do XIX, acompanhando a ascensão do regime do capital, estendeu-se progressivamente a duração do trabalho que atingiu, na primeira metade do século XIX, limites intoleráveis. ${ }^{2}$ A seguir, no longo período que percorre a segunda metade do século XIX e o século XX, assistiu-se ao movimento inverso, de lenta redução da duração do trabalho.

Assim, nos primórdios da Revolução Industrial Britânica, as condições de vida e trabalho se tornaram insustentáveis. As lutas operárias, a explosão de conflitos urbanos, a penúria extrema das classes trabalhadoras ameaçava, inclusive, as condições de reprodução da força de trabalho, fazendo crescer o sentimento de que a exploração sem limites acabaria por minar a força do poderio britânico. ${ }^{3}$

Observou-se, a seguir, um lento processo de regulamentação, de institucionalização e de controle da duração do trabalho, acompanhado pela conscientização, nos meios operários e sindicais, da importância da luta pela definição dos limites da exploração do trabalho.

Para os fins de nossa exposição, num primeiro registro, a ideia da RTT aparece em seu sentido "formal" nos limites das estratégias de maximização, ou seja, na perspectiva de seu não afrontamento com as condições ditadas pela valorização do capital, sujeita aos constrangimentos da busca pela eficiência, da ampliação da produtividade e da competitividade. Estes são os contornos, por exemplo, de grande parte do debate na França por ocasião das 35 heures. Naquele momento, economistas detratores da RTT apegavam-se aos ditames dos custos do trabalho, da competitividade, nos marcos dos modelos de equilíbrio de inspiração neoclássica (Fracalanza, 2008). Mas mesmo os defensores da proposta viam-se presos, na maioria das vezes, aos estreitos limites ditados pela economia tradicional, procurando arduamente demonstrar que a RTT poderia, de fato, produzir um crescimento mais rico em empregos sem afrontar as condições de rentabilidade do capital.

Já em seu segundo significado, a RTT aparece em seu sentido "substantivo", apontando para a possibilidade de superação do primitivo problema

2 O que estava em jogo não era apenas o incremento da taxa de exploração da mão de obra, mas a disposição em sujeitar a nascente classe trabalhadora às determinações e à disciplina do capital. Conforme Marx, O capital, 2013, (original de 1867), no capítulo VIII.

3 "Abstraindo de um movimento dos trabalhadores que se torna a cada dia mais ameaçador, a limitação da jornada de trabalho nas fábricas foi ditada pela mesma necessidade que forçou a aplicação do guano nos campos ingleses. A mesma rapacidade cega que, num caso, exauriu o solo, no outro matou a força vital da nação" (Marx, 2013, p. 313). 
da humanidade: a necessidade de trabalho para a subsistência humana. O sentido das propostas substantivas da RTT pode iluminar a utopia de um mundo sem trabalho, ou em que o trabalho heterônomo ocupe uma pequena parcela do tempo dos homens e mulheres, em razão do já excepcional avanço das forças produtivas. Articulam-se, ainda, nesse conceito, ademais da libertação do fardo do trabalho, a possibilidade de a humanidade também liberar-se da patologia da acumulação insensata e das ideias naturalizadas de uma humanidade movida pelo egoísmo, pela cupidez e pela violência no seu afã de consumo irrefreável. Surgem, portanto, os ideais de uma vida mais plena, mais sábia e mais coerente com seu enquadramento e dependência com relação aos sistemas naturais. Esse movimento inicia-se, como dito, com a recuperação das contribuições do que chamamos aqui de "precursores da RTT em seu sentido substantivo" para, posteriormente, analisar propostas contemporâneas intimamente relacionadas aos limites impostos pela problemática ambiental.

\section{Precursores da RTT em seu sentido substantivo}

\subsection{Keynes e a barganha faustiana}

Para John Maynard Keynes, o grande problema do capitalismo repousaria justamente em sua busca incansável pela valorização do capital. Ainda assim, ele acreditava que esse sistema, em sua expansão, seria capaz de libertar o homem de seu maior e mais primitivo problema econômico: o fardo do trabalho na luta pela subsistência.

Keynes apresenta sua visão utópica em um ensaio de 1930, intitulado "Possibilidades econômicas para nossos netos". Em tom otimista, mas não sem sutil ironia, o autor "abre asas para o futuro". Prognosticava jornadas diárias de três a quatro horas, suficientes para suprir as necessidades básicas e de conforto do ser humano, possibilitadas pelo avanço desimpedido das forças produtivas, impulsionado pelo progresso técnico, pela divisão do trabalho e pela disciplina imposta pelo capital. Nesse futuro, entrevia a ressignificação dos papéis do trabalho e do tempo livre e dos horizontes de uma vida mais plena. Contrapondo-se aos revolucionários "que pensam que as coisas estão tão ruins que nada pode nos salvar a não ser a mudança violenta" e dos reacionários "que consideram o balanço da vida 
econômica e social tão precário que nós não deveríamos arriscar nenhum experimento", o autor apresenta uma postura reformadora afirmando que a tendência não vislumbrada por aqueles cegos pelo pessimismo era o potencial "libertador" do capitalismo: sua capacidade de gerar uma nova realidade social.

Ao se dar conta dessa nova realidade, denominada good-life ou bliss, a busca desenfreada pela acumulação monetária perderia sentido. Livre do trabalho, o ser humano não mais encontraria sentido na busca e acumulação desenfreada de dinheiro (love of money). Libertos do trabalho, homens e mulheres poderiam e deveriam devotar seu tempo livre à valorização do bom e não do útil, à contemplação do belo, da arte e da natureza e à edificação de relações humanas verdadeiras (leia-se, não pecuniárias).

Pois bem, a RTT surge como consequência da transição do capitalismo para outro "estado das coisas" em que as necessidades absolutas - aquelas que sentimos independentemente da situação de outrem - seriam supridas e as necessidades relativas - aquelas que dependem da comparação com outras pessoas - não fariam mais sentido. $O$ trabalho já não mais seria um fardo, mas sim o exercício benfazejo da necessidade humana desde Adão de transformar o ambiente ao seu redor. O capitalismo para Keynes seria, portanto, um mal necessário, uma barganha faustiana (Skidelsky; Skidelsky, 2012), que embora detestável, permitiria a transição para uma vida plena de realizações.

Todavia, esse futuro só poderia de fato ocorrer se cumpridas algumas condições. A solução do problema econômico nos próximos 100 anos exigiria a ausência de guerras e convulsões sociais, controle do aumento populacional e confiança na ciência das matérias que são seus objetos (Keynes, 1963; p. 373).

Já muito próximos da geração dos netos de Keynes, constatamos que o futuro por ele imaginado não parece nem perto de se realizar. O rumo que tomamos como sociedade, com a progressiva centralidade do consumo na construção da identidade e pertencimento sociais, nos afasta das previsões de Keynes. A atualidade do economista e de seu registro indica que o sistema de relações sociais que forjamos poderá comprometer irremediavelmente a possibilidade de nossos netos herdarem uma Terra que lhes permita viver com dignidade. ${ }^{4}$

4 Para a referência dos "impulsos de morte" do capitalismo de inspiração freudiana, ver, sobretudo, Maris e Dostaler (2009). 


\subsection{Russell e a moral escravista e servil}

Bertrand Russell, contemporâneo de Keynes, também aborda a RTT como uma mudança social desejável em The praise of idleness (1932). Nessa obra, propõe que a crença na virtude do trabalho, dogma incrustado na cabeça dos homens por séculos, não estaria de acordo com o "mundo moderno", pois "a moral do trabalho é uma moral de escravos, e o mundo moderno não precisa de escravidão" (Russell, 1932).

Numa aproximação com Keynes, o autor afirma que do início da civilização até o advento da Revolução Industrial o homem ocidental teve sua vida marcada pela necessidade premente de trabalho para a sobrevivên$\mathrm{cia}^{5}$, pois "um homem em geral era capaz de produzir, trabalhando arduamente, um pouco mais que o necessário para a própria subsistência e a de sua família...". Nesses tempos, o excedente do trabalho era apropriado pelos guerreiros e sacerdotes, aos quais a virtude do trabalho não se aplicava. Ao lado disso, a moral cristã católica via o trabalho como castigo bíblico. A organização do trabalho foi se transformado no contexto da Revolução Industrial, mas Russell considera que sua dimensão moral estava tão enraizada que conseguiu sobreviver ao surgimento da sociedade industrial moderna. Para ele, a manutenção dessa moral seria antiquada, pois a nova sociedade industrial demonstrara que uma jornada de quatro horas seria suficiente para que todos desfrutassem de uma vida confortável (Russell, 1932, p. 12).

Para Russell, ao contrário do credo dominante, o tempo livre dos pobres não seria necessariamente preenchido de forma frívola, pois, liberta do trabalho, a humanidade poderia dedicar-se à cultura, à curiosidade científica e ao lazer ativo. A redução do tempo de trabalho seria uma realidade imediata para Russell, que apontava: "com a oportunidade de uma vida feliz, homens e mulheres comuns se tornarão mais amáveis e menos intransigentes, menos inclinados a julgar os outros com suspeição. $\bigcirc$ gosto pela guerra se extinguirá, em parte por essa razão e em parte porque implicará longo e árduo trabalho para todos" (Russell, 1932, p. 24).

5 O termo ocidental não está nas palavras do autor, mas foi adicionado para esclarecer que Bertrand Russell referia-se especificamente à história do Ocidente e, mais especificamente ainda, da Europa. 


\subsection{Lafargue e o elogio à preguiça}

Paul Lafargue foi um revolucionário franco-caribenho casado com Laura Marx, que militou ao seu lado, especialmente após a morte de seu pai, Karl Marx. Escreveu em 1880 um panfleto - "Le Droit à la Paresse", publicado originalmente na forma de artigos no jornal L'Égalité - no qual criticava o "dogma desastroso" do trabalho compartilhado por liberais, conservadores e mesmo por marxistas.

O cenário francês do mundo do trabalho foi inspiração para o polêmico texto. O momento observado por Lafargue era o de um capitalismo em expansão. Na vanguarda de Keynes e Russell, considerava o progresso técnico como libertador do trabalho humano, e a invenção da máquina, a "redenção da humanidade". As máquinas seriam como "o Deus que resgatará os homens da sórdida arte e do trabalho assalariado, o Deus que lhes oferecerá o dom do ócio e da liberdade" (Lafargue, 1965, p. 78). Essa libertação estaria sendo adiada pela cegueira dos operários, que não se davam conta de que o "dogma do trabalho" seria o causador de todas as suas misérias.

Lafargue observara a revolução promovida pelas máquinas nos teares ingleses já no final do século XIX. As mudanças propiciavam claras condições para a redução do tempo de trabalho. Enquanto uma "boa operária realiza com o fuso não mais do que cinco malhas por minuto, alguns teares circulares fazem até 30 mil no mesmo espaço de tempo". Entretanto, sua percepção era a de que os próprios operários se entregavam ao vício do trabalho, produzindo mais do que o necessário, contribuindo para a crise de superprodução, criando pressupostos para o consumo supérfluo, desejando competir com a máquina - "que concorrência absurda e mortífera!" Em vez de exigirem uma vida ociosa como a dos ricos, estendiam também a estes a obrigação de trabalhar (Lafargue, 1965, pp. 57-58).

Para o autor, o desenvolvimento da sociedade industrial poderia libertar mulheres e homens do fardo do trabalho, mas no sentido da orientação política Lafargue advoga a necessidade de ação dos próprios trabalhadores. A redução do tempo de trabalho e o "direito ao ócio" só sucederiam quando o proletariado recusasse o amor ao trabalho e rompesse com o pensamento da classe dominante que, ao mesmo tempo que alimenta o dogma de "quem não trabalhar não comerá", usufrui do ócio e vive à custa do trabalho dos operários. 
Lafargue acreditava que a consciência de classe dos operários poderia tornar possível uma jornada diária de apenas três horas para todos os cidadãos, ricos e pobres. Antevia, porém, como Keynes, dois obstáculos: como educar para o ócio e para o consumo um proletariado doente por excesso de trabalho e por abstinência; e como educar para o trabalho e para a sabedoria uma burguesia habituada ao ócio e ao consumismo supérfluo?

\section{Três perspectivas contemporâneas}

Crescimento econômico, produtividade, extensão e intensidade das jornadas de trabalho são alguns dos assuntos sob as lentes de alguns autores contemporâneos que se põem a examinar de forma não convencional e criativa as interfaces entre os domínios social, econômico e ambiental. Alinhados naquilo que pode ser compreendido como um conjunto de reflexões orientadas à ação que não pode ser axiologicamente neutra, uma vez que a noção de fronteiras planetárias - ou limites - se torna um postulado ético, destacam-se neste artigo três autores. ${ }^{6}$ Além da concordância com respeito a uma ação axiologicamente não neutra, esses autores preconizam que a RTT esteja alinhada a prescrições de um "decrescimento administrado". Observemos algumas contribuições desses três intelectuais: André Gorz, Tim Jackson e Dominique Méda.

\subsection{Gorz e a Ecologia Política}

André Gorz (Viena - 1923, França - 2007), filósofo e jornalista, foi seguramente um dos mais destacados teóricos da Ecologia Política e das abordagens do decrescimento. Sua vasta obra, instigante, crítica e libertária reflete as influências de Marx, do existencialismo de Sartre e de alguns de seus amigos e intelectuais da Escola de Frankfurt.

Em vista de nossos propósitos nesta apresentação, algumas de suas ideias merecem destaque: sua impiedosa crítica à alienação da humanidade no capitalismo, sua perspectiva ecológica alicerçada no terreno da crítica ao consumismo e sua crença de que os limites últimos à nossa civi6 A noção de "fronteiras planetárias" foi proposta por Rockström et al. (2009) para definir as condições biogeofísicas para o desenvolvimento humano. 
lização podem ser contornados por uma ética de libertação que permitiria romper com o domínio das técnicas específicas de nossa forma de organização social sob a égide do capital, as quais exercem sua dominação sobre os homens e a natureza.

Para Gorz, a questão das formas de subjetivação no capitalismo é de vital importância. No regime do capital, as esferas de instrução, educação, socialização e integração produzem indivíduos úteis e dóceis, prontos a executar seus papéis nas engrenagens do que denomina de "megamáquina social". ' O adestramento requer que os indivíduos interiorizem os imperativos do controle dos tempos, da lógica do "quanto mais, melhor", da rejeição à categoria do "suficiente" e do "necessário".

Em sua máxima, "o capitalismo necessita de pessoas que tenham maiores desejos". Sua descrição do marketing, das técnicas de venda, do frenético surgimento de inovações que incorporam o supérfluo no necessário, que atendem aos requisitos da obsolescência programada e, sobretudo, do processo de gradual eliminação dos consumos e serviços coletivos em prol dos consumos individuais, permite-nos descortinar sua crítica radical ao consumismo, à alienação e à vida insensata nas metrópoles.

Nesse sentido, seu ensaio intitulado "A ideologia social do automóvel" é exemplo dessa singular démarche. Gorz (2008) nos propõe ver o automóvel com um olhar de estranhamento e revisitar nossas cidades e subúrbios, seu adensamento e extensão desmesurados, a proporção das vias pavimentadas e a imensa indústria que se cria a montante e a jusante dessas maquinarias. Se essas formas de transporte, pela primeira vez, exigem que seus condutores se submetam à intervenção especializada de um exército de serviçais - frentistas, borracheiros, mecânicos, funileiros, guardadores de carros, entre outros - o dispêndio de tempo para a locomoção, cada vez mais dilatado nos grandes centros urbanos, deve ser necessariamente acrescido, afirma Gorz, ao tempo de trabalho dedicado à produção de um valor equivalente àquele materializado no automóvel. Se somarmos ao tempo dos trajetos casa-trabalho o tempo dedicado à produção de valor equivalente ao imobilizado no automóvel, facilmente verificaremos que a velocidade média alcançada pelas novas máquinas pouco excede a de um transeunte a pé, com a diferença agora que as distâncias foram multipli-

7 Incursão semelhante é realizada por Dardot e Laval em A Nova Razão do Mundo.

8 Conforme Gorz em Metamorfoses do Trabalho, 2007, p. 109 e seguintes. 
cadas para acomodar o fluxo dos automóveis que abarrotam as cidades.

$\mathrm{Na}$ leitura de Gorz, chega-se inevitavelmente à Ecologia Política, "com sua indispensável teoria crítica dos desejos, que conduz novamente ao aprofundamento e radicalização da crítica ao capitalismo". Em outras palavras, o ponto de partida da Ecologia Política funda-se numa exigência ética de emancipação dos sujeitos e não numa suposta moral ecológica, ou num ecocentrismo. Ao contrário, Gorz rejeita o que denomina de um "imperialismo ecológico" que em sua visão pode descambar para soluções totalitárias que continuariam a aniquilar as possibilidades de emancipação e do exercício da autonomia. A ecologia apenas adquire sua dimensão crítica e ética se a destruição das bases naturais da vida na terra for corretamente compreendida, ou seja, como resultado da operação de uma forma singular de produção e de consumo que, recorrendo à maximização do rendimento e da produtividade e da miragem do crescimento ilimitado, destrói a teia da vida. Nesse sentido, Gorz aproxima-se, em nossa visão, do conceito de economia em seu sentido "substantivo", tal qual formulado por Polanyi (2012), qual seja, o de que a humanidade não pode subsistir sem um meio material adequado que garanta o seu sustento.

Portanto, na visão do autor, no regime do capital não se encontram as condições para a superação das formas que destroem a natureza e aniquilam as possibilidades de libertação e autonomia para homens e mulheres. Uma sociedade fundada em outra ética, dotada de outros valores, talvez construída a partir da integração de comunidades menores, cercadas de cinturões verdes, alicerçadas nos valores comunitários e no desabrochamento das aptidões individuais, onde as jornadas de trabalho, no sentido heterônomo serão reduzidas, e onde os deslocamentos se farão a pé, ou em bicicletas, talvez constitua utopia possível de saída do capitalismo.

\subsection{Jackson e a prosperidade sem crescimento}

Tim Jackson é um economista britânico, da Universidade de Surrey (UK) que, em 2009, publicou Prosperity without Growth, desdobramento do relatório por ele preparado na liderança da Comissão para o Desenvolvimento Sustentável, criada em 2001.

O propósito do livro é pensar a noção de prosperidade para além de uma dimensão economicamente restrita. Uma prosperidade partilhada 
socialmente e ajustada às fronteiras planetárias, o que levou o autor a retomar o debate sobre o crescimento. Para a discussão central deste artigo, que diz respeito ao debate sobre a RTT, interessa recuperar o tratamento dado pelo autor ao assunto, o que ocorre em dois momentos de seu livro. $\mathrm{O}$ primeiro, mais teórico e positivo, tem lugar quando o autor enfoca a necessidade de uma "macroeconomia ecológica", que deveria substituir a macroeconomia convencional, cujas abordagens tanto no campo ortodoxo quanto heterodoxo são pautadas por uma visão de mundo na qual o crescimento é um objetivo central. O segundo momento, mais propositivo e político, é quando o autor propõe recomendações que decorrem logicamente da análise empreendida para a transição rumo a uma economia sustentável. A seguir, focalizamos cada um desses momentos.

Do ponto de vista teórico/positivo, sugere uma "macroeconomia ecológica", em cujo edifício conceitual o crescimento não gozaria de uma centralidade. Confinada à escala ecológica, a atividade econômica se voltaria à realização humana. Seria preciso alfabetizar a teoria macroeconômica na sintaxe da ecologia, seguindo caminhos abertos por Georgescu-Roegen (1971; 1975) e Daly $(1974 ; 1991)$.

Jackson está convencido de que uma macroeconomia para a sustentabilidade não apenas é essencial, mas tecnicamente possível. O ponto de partida residiria na identificação clara das condições de sustentabilidade, incluindo a proteção do florescimento das capacidades humanas, a equidade distributiva, níveis sustentáveis de transumo e de emissões e a proteção de um capital natural crítico. Um aspecto fundamental para o qual o autor chama a atenção:

[nos modelos convencionais de crescimento] (...) quando a produtividade do trabalho aumenta ao longo do tempo, como se admite geralmente em razão de um aperfeiçoamento tecnológico, a única maneira de estabilizar a produção econômica (...) consiste a reduzir o fator trabalho (...) ou, em outros termos, a aceitar um certo subemprego

inversamente (...), quando a demanda cai, as receitas das empresas se reduzem, levando a perdas de emprego e a reduções no investimento. Essa última leva a uma baixa do estoque de capital que, conjugada com uma redução do fator trabalho, diminui por sua vez a capacidade produtiva da economia. A produção cai $e$, estando reduzida a quantidade de dinheiro disponivel na economia, as receitas públicas são diminuidas por seu turno, o endividamento aumenta e o sistema mostra uma tendência à instabilidade.

É no fundo esta dinâmica que está na origem da insistência dos economistas sobre o fato de que o crescimento contínuo é essencial para a estabilidade econômica no longo prazo (Jackson, 2009, pp. 132-3; tradução dos autores). 
Decifrar esse caráter tautológico do raciocínio que propõe o crescimento permanente como forma de se evitar a instabilidade é tarefa que remete a duas dimensões complementares do trabalho de Jackson. De um lado, uma dimensão que alinha esse autor às preocupações de Gorz: o ceticismo a respeito de que mudanças essencialmente tecnológicas sejam suficientes para o enfrentamento da crise socioambiental. Jackson considera que, sem a modificação do caráter consumista e produtor de resíduos em larga escala em nossas sociedades, essas mudanças significariam apenas a manutenção e, provavelmente, o aprofundamento da crença no mito do crescimento indefinido. De outro lado, o questionamento sobre alternativas para a compreensão da prosperidade não necessariamente atrelada ao crescimento do PIB.

A prosperidade sem crescimento passa por uma revisão da natureza do próprio crescimento, à la Ayres (2008), a qual implicaria a mudança de foco da economia do "produto", ou sua "desmaterialização", para "serviços". Tal economia estaria muito distante da terceirização em voga, especialmente nos países de capitalismo avançado de nossos dias graças à ampla difusão das tecnologias de informação e de comunicação. Também não seria essa economia aquela que mais cresce hoje. A forma de ocupação do tempo em atividades de lazer, por exemplo, que consome cada vez mais o tempo livre nos países centrais, é responsável por cerca de $25 \%$ da pegada carbônica nesses países (Jackson, 2009, p. 134).

No prefácio à edição francesa, o filósofo Patrick Viveret (2009) considerava oportuna a retomada proposta por Jackson (2009) de trabalho anterior de Peter Victor, macroeconomista canadense. Victor (2008) usou modelos computacionais para estudar a maneira pela qual a economia canadense reagiria a uma parada no crescimento. Os resultados obtidos por Victor (2008) se mostraram muito sensíveis a valores como a taxa de poupança, as taxas de investimento público e privado e a duração da semana de trabalho.

Jackson explorou os resultados dos dois modelos concebidos pelo autor na defesa de uma macroeconomia da sustentabilidade. No primeiro deles, sugere-se que seria possível, sob certo número de hipóteses, estabilizar a produção econômica mesmo numa macroeconomia bastante convencional. Políticas de emprego representariam papel essencial para impedir o aumento do desemprego. O segundo modelo observa as implicações macroeconômicas de um afastamento dos combustíveis fósseis. Demonstra- 
-se que pode haver uma estreita "janela de sustentabilidade" através da qual a economia poderia passar se fosse o caso de realizar com sucesso essa transição. Essa janela seria ampliada se uma parcela maior da renda fosse alocada para poupança e investimento.

Esses exercícios ilustram possibilidades para uma nova macroeconomia, voltada para a sustentabilidade, com maior resiliência. $O$ ponto de partida residiria na identificação clara das condições para uma economia sustentável, incluindo forte requisito para a estabilidade econômica como forma de proteger tanto os empregos das pessoas quanto o florescimento de suas capacitações. Todavia, precisariam ser suplementadas por condições que assegurassem a equidade distributiva, estabelecessem níveis sustentáveis de transumo e de emissões, e favorecessem a proteção de um capital natural crítico. Em termos operacionais, existiriam diferenças importantes na forma como as variáveis convencionais haveriam de funcionar nessa nova macroeconomia. O balanço entre consumo e investimento, a divisão entre gastos dos setores público e privado, a natureza do aumento de produtividade, as condições de lucratividade: todas essas variáveis precisariam ser "renegociadas" politicamente. Há, portanto, uma visão, tanto em Victor (2008) como em Jackson (2009), de que seria imprescindível um novo pacto social a respeito dos fins - e dos meios - nas decisões e práticas sobre a produção e a reprodução material de nossa vida social, levando em conta ainda, a redução dos resíduos e o aumento das capacidades sociais e ecológicas para sua reciclagem.

O papel do investimento seria, como sempre, crucial. A sustentabilidade demandaria o avanço de investimentos em infraestruturas públicas, em tecnologias sustentáveis e na manutenção e preservação ecológicas. Logicamente, uma nova macroeconomia para a sustentabilidade precisaria abandonar o pressuposto do crescimento do consumo material como a base da estabilidade econômica. Essa nova ciência e técnica teria que ser alfabetizada em termos ecológicos e sociais, terminando com a separação da esfera da economia com relação às da sociedade e do ambiente natural (Viveret, 2009, p. 10).

Do ponto de vista propositivo e político, uma prosperidade sem crescimento demandaria uma mudança na lógica social, mas não se limitaria a ela. Aprisionada no consumo materialista, a lógica atual combina poderosamente a construção de identidades, formas de participação na vida social, articuladas com excessos da produção e da acumulação. 
De acordo com Jackson (2009), urge o alcance de condições para a liberação dessa dinâmica psicológica, social e ambientalmente perniciosa. Ele observa que, na medida em que o crescimento tem significado o acirramento dos conflitos socioambientais, o aprofundamento da desigualdade e da violência, a degradação de recursos naturais e a quebra da resiliência dos ciclos biogeoquímicos que sustentam a vida no planeta, a lógica imperativa do crescimento se coloca em conflito insuperável com a busca de outros objetivos sociais e ambientais. $\mathrm{O}$ autor reconhece o papel do consumo na construção de identidades e como amálgama na construção de laços sociais. Essa dimensão do consumo, no entanto, precisa ser reconstruída num mundo em que a posse de bens - e seu contínuo e acelerado descarte - se sobrepôs às relações sociais. É preciso, segundo Jackson (2009), que o consumo recupere seu status coletivo, observando uma multiplicidade de espaços na vida social em que o consumo comum perdeu lugar e que deveria recobrá-lo: nos cuidados com o outro e nos cuidados de si, no lazer, na cultura, na educação, na saúde. Em toda uma gama de serviços, enfim, que tem sido tomada por uma vigorosa onda que tende a mercantilizar os espaços de convívio e de cuidados.

A sobreposição do consumo ao ordenamento das relações sociais não monetárias já foi abordada por outros autores, como, entre outros, Judt (2011), Lipovetsky (2007) e Bauman (2008). O olhar de Jackson a respeito disso se desdobra com sua insistência em rechaçar, como solução geral para os problemas de ordem socioambiental, a busca daquilo que outros apontam como uma espécie de bala de prata: a produtividade. Apenas para tocar com brevidade na contra-argumentação de Jackson diante dessa solução, observem-se dois pontos.

O primeiro ponto diz respeito ao fato de que, diante da problemática ambiental, a solução geral de uma maior produtividade, que pode significar o uso de menos recursos ou energia por unidade de produto, em geral tem levado ao efeito rebote (rebound effect ou efeito Jevons). Significa que essa redução em termos unitários acaba por ser mais que compensada pelo aumento no consumo total do produto em questão, ou conjunto de produtos, significando, ao final, o aumento no uso total dos recursos (ou da energia). Essa é a principal razão pela qual Jackson não subscreve a teoria do "descolamento" (decoupling) do crescimento do PIB do uso dos recursos e da energia.

O segundo ponto tem mais a ver com a problemática social do desemprego, embora Jackson também observe que possam existir vinculações 
com os resultados em termos de emissões de gases de efeito estufa. Nesse caso, haveria um farto conjunto de atividades econômicas - sobretudo os serviços, conforme apontamos mais anteriormente - em que a busca da produtividade simplesmente não faria sentido. Deveria ser evidente que não se poderia esperar produtividade de enfermeiras e outros profissionais da saúde que cuidam de bebês prematuros, idosos ou pessoas com necessidades especiais. E a busca pela produtividade parece ter algum limite quando se trata de saúde em geral. $O$ mesmo poderia ser dito a respeito da educação, da pesquisa científica, de inúmeros cuidados pessoais, para não falar da produção artística. Jackson lembra, a esse respeito, que em seu famoso artigo sobre cost disease, Baumol \& Bowen (1965) observaram não haver sentido que os músicos de uma orquestra tivessem seus salários determinados pela produtividade marginal de seu trabalho. Ninguém teria seu bem-estar melhorado se os músicos executassem uma sinfonia com o dobro da velocidade.

Há, em Jackson (2009), muitos graus de liberdade para a ação política visando à reconstrução de um mundo do trabalho no qual este pudesse ser executado não apenas de forma a atender com mais dignidade suas respectivas demandas. Essa reconstrução ofereceria também a possibilidade de resgatar outras dimensões significativas do próprio trabalho.

Assim, entre outras recomendações, Jackson (2009) destaca a RTT que apenas poderia fazer sentido num mundo em que também fossem enfrentados outros desafios como a luta contra as desigualdades sistêmicas, o dimensionamento das capacitações e de seu desenvolvimento, o reforço do capital social e o desmantelamento da cultura do consumismo.

Numa prosperidade sem crescimento seria, enfim, essencial, embora não suficiente, a RTT, com o alcance de um melhor balanço entre vida profissional e vida privada. Para alcançá-lo, o autor propõe ainda a maior flexibilidade no tempo de trabalho, ações para combater discriminações contra os trabalhadores em tempo parcial, melhores incitações para o tempo passado em família e períodos sabáticos e de licenças parentais.

\subsection{Méda e a modificação do trabalho na reconversão ecológica}

Dominique Méda, professora de sociologia da Université Paris-Dauphine e diretora do Instituto de Pesquisa Interdisciplinar em Ciências Sociais 
(IRISSO), é autora de diversas obras sobre transição ecológica, entre elas o livro La mystique de la croissance: comment s'en libérer?, de 2014.

A crise ambiental, descrita e analisada por cientistas naturais e sociais contemporâneos, enquadrada por meio das lentes de uma sociologia cultural permite a Méda compor uma síntese sobre a mistificação do crescimento em nossas sociedades. Diante da compreensão científica dessas crises, a autora resume seu ponto: "A crença segundo a qual o crescimento seria a chave da prosperidade e do progresso, e que deveria permanecer como o objetivo de nossas sociedades, encontra-se abalada" (Méda, 2014, p. 10).

Circunstanciar a posição da RTT no seio de visão de futuro da autora requer acompanhar um ponto de partida caro a Méda: sua perspectiva crítica sobre a concepção prevalente de riqueza e progresso, e suas métricas. A seguir, visitamos três pontos levantados por Méda (2014; 2016) em sua apreciação das limitações do PIB como medida da riqueza e do progresso social.

Primo, a exclusão de atividades não voltadas à produção para a troca mercantil. O PIB não leva em conta um conjunto de atividades carregadas de sentido para as pessoas e para as sociedades. Atividades muito consumidoras de tempo, como são os casos das tarefas familiares e domésticas, realizadas no lar com outras finalidades que não a transformação para a troca, compreendendo os relacionamentos amicais, amorosos, cidadãos, voluntários e de lazer. São atividades que representam um engajamento de tempo tão ou frequentemente mais considerável que o tempo de trabalho, mas que não são contabilizadas. Há um arrazoado lógico, dentro da macroeconomia, sobre as razões pelas quais essas atividades não devem compor os cálculos do PIB. Mas isso significa não dar conta de sua contribuição para o sentido de progresso e de bem-estar em nossas sociedades. $\mathrm{Na}$ contabilidade nacional, a redução brutal dessas atividades e mesmo seu total desaparecimento não seria de forma alguma assinalada como perda. Pior, caso essas atividades fossem transferidas ao mercado, isso se traduziria por um aumento do PIB, sem menção em parte alguma da perda de valor ligada ao desaparecimento de atividades cuja finalidade não é redutível à produção de bens e de serviços (Méda, 2016, p. 286).

Secundo, a não contabilização dos estoques. O cálculo do PIB envolve lançamentos de fluxos; não constitui contabilidade patrimonial. Ou seja, o cálculo do PIB não leva em conta a evolução de patrimônio, seja físico, seja humano, que uma sociedade mobiliza e utiliza para fabricar produtos e serviços. Levar em conta, ao lado dos fluxos, a evolução de estoques 
físicos, a riqueza natural ou a evolução da qualidade de certos elementos do patrimônio natural - o clima, as florestas, a diversidade da vida, a fertilidade e integridade dos solos, os rios e lagos, por exemplo - seria algo revolucionário nessa contabilidade. Uma das distorções hoje observadas, com relação ao cálculo do PIB, é que é perfeitamente possível contabilizar taxas de crescimento econômico elevadas, lado a lado com uma degradação radical e irreversível do patrimônio natural. Ora, a riqueza e a diversidade desse patrimônio é o que permite e sustenta a existência das sociedades humanas e da própria vida no planeta. A degradação dessa riqueza e da diversidade que lhe é inerente é o que se observa com o avanço das mudanças climáticas, com a perda da biodiversidade, poluição do ar, das águas, dos solos e dos oceanos. Essa degradação ameaça, em horizontes cada vez mais próximos, tornar impossível a própria produção econômica (Méda, 2016, p. 286-287).

Tertio, a insciência sobre os bens comuns. Méda argumenta que esses bens (recursos ou serviços) - e sua eventual degradação - são ignorados nos cálculos do PIB (Méda, 2016, p. 287).

Sabemos que não é recente o reconhecimento das limitações do PIB como medida de bem-estar. Iniciativas significativas têm proposto outras visões sobre o próprio conceito de bem-estar, ou de prosperidade, e, de forma correspondente, o desenvolvimento de outras métricas para sua mensuração.

A iniciativa do Banco Mundial (2006), consolidada no relatório Where is the Wealth of the Nations? Measuring Capital for the Twenty First Century, procurou estimar monetariamente os diferentes capitais (produtivos, humanos e naturais) de modo a comparar sua soma intertemporalmente, ano a ano. A maneira pela qual esse capital é concebido e representado, no entanto, como Méda (2016) nos exorta a analisar, importa no mais elevado grau. Trata-se de uma concepção fraca da sustentabilidade, uma vez que a degradação de um tipo de capital pode ser compensada pelo melhoramento de outro. Uma representação como essa é radicalmente diferente de uma perspectiva que leve em consideração a evolução de patrimônios reais, notadamente de dois entre eles que condicionam a existência das sociedades: o patrimônio natural - a quantidade e a qualidade dos patrimônios considerados como críticos (os oceanos, os solos, as florestas, os lençóis freáticos e as reservas de água, os recursos naturais renováveis e não renováveis, o ar) - e a saúde social - as condições de vida, notadamente, o acesso aos re- 
cursos e aos direitos indispensáveis dos diferentes membros da sociedade. Esses dois tipos de representação dos capitais ou dos patrimônios que contam são, como podemos ver, radicalmente diferentes (Méda, 2016, p. 288).

Outra iniciativa muito conhecida partiu da constituição de uma Comissão sobre Medidas de Performance Econômica e de Progresso Social, chamada também de Comissão Stiglitz, que teve seu relatório publicado em 2009. O relatório, uma coautoria de economistas célebres, incluindo os Prêmios Nobel de Economia Joseph Stiglitz e Amartya Sen, além do economista convencional ligado ao establishment francês, Jean-Paul Fitoussi, constituiu um momento importante no debate sobre o conceito de bem-estar e prosperidade e suas possíveis mensurações (Stiglitz; Sen; Fitoussi, 2009). A Comissão convida a completar o PIB "com outros indicadores, se pronunciando, contudo, contra indicadores sintéticos e renunciando finalmente à promoção de certos indicadores, tais como a poupança líquida ajustada, em favor da qual o relatório intermediário havia se pronunciado" (Méda, 2016, p. 287-288).

A Comissão avançou em três proposições principais, como sintetiza Méda: integrar melhor as desigualdades de renda na determinação do PIB; mensurar melhor a qualidade de vida e mensurar melhor a sustentabilidade. Com relação a esse terceiro ponto, a Comissão surpreende, recomendando que se leve em conta tanto o estoque (patrimônio, riqueza) quanto os fluxos (rendimentos e consumo). Com relação aos fluxos, a Comissão adverte que, embora sejam essenciais para avaliar os níveis de vida, eles não podem servir simplesmente como ferramenta de apreciação dos estoques. Essa proposição representa uma importante reversão, de acordo com a autora. É uma visão que deixa para trás uma concepção na qual a riqueza é concebida como o aumento de um fluxo (a produção ou o valor adicionado a cada ano) em favor de uma ideia, muito distinta, que propõe que a riqueza deve ser vista como o crescimento de um estoque, de um ativo (ou ainda de um capital, de um patrimônio, de um fundo, de um conjunto de realidades).

Persiste, ainda, o problema da monetização da riqueza. O fundamento filosófico da concepção da riqueza como valor monetário da soma de diferentes tipos de capitais se encontra, como ajuíza a autora, na certeza de que sempre haverá suficientemente capital humano e capital técnico capazes de transformar forças humanas em progresso técnico, inclusive para suprir o equivalente ao capital natural. Pouco importa que este seja pouco 
a pouco destruído, os seres humanos seriam suficientemente inteligentes para produzir um capital artificial que gerará para a humanidade um fluxo de utilidades (serviços, por exemplo) equivalente àquele que hoje é gerado pelo capital natural. Nessa concepção de riqueza, pouco importa que esses fluxos provenham de estoques tecnológicos ou naturais.

A descrença na flexibilidade e substitutibilidade entre os estoques de riqueza, pressupostas na visão fraca de sustentabilidade, é uma razão para a não concordância de Méda com a tese de que a revolução digital atualmente em andamento, se bem que geradora de perdas de empregos (Brynjolfsson; McAfee, 2011; 2014), seria fortemente criadora de riquezas e constituiria a verdadeira via de saída da crise. Esta é a tese defendida por vários dos economistas reunidos na obra publicada no final de 2014 com o título de Secular Stagnation: Facts, Causes, and Cure (Teulings; Baldwin, 2014). De acordo com Brynjolfsson e McAfee (2011), os benefícios da "Grande Reestruturação" atualmente em curso não seriam ainda visíveis nas estatísticas do PIB, em razão de uma simples decalagem temporal e pelo fato de este indicador ainda não ser capaz de tornar visíveis os ganhos de bem-estar.

A tese segundo a qual a revolução digital seria o gatilho de uma nova etapa na dinâmica do crescimento mundial apresenta, na visão de Jany-Catrice e Méda (2016), que retomam e ampliam a discussão de Gadrey (2015), limites determinantes: ela se apoiaria num forte determinismo tecnológico; não levaria em conta as resistências das sociedades envolvidas; não evocaria o caráter energo-intensivo e altamente consumidor de metais raros dos processos envolvidos; não levaria em conta as restrições ecológicas às quais as sociedades estão hoje confrontadas; e silenciaria sobre a necessidade de ruptura na qual deveríamos nos engajar, com mudanças fundamentais em nossos comportamentos. Além disso, essa tese seria totalmente alheia à necessidade, defendida pela autora, de uma reformulação da episteme positivista do progresso que guia nossas ações pelo menos desde o século XVIII (Méda, 2016, p. 289).

Avançando no argumento da autora, haveria nesses nossos tempos de crise uma oportunidade transformadora de reconexão entre certa forma de pleno emprego e a modificação do trabalho. Essa oportunidade foi divisada por Gadrey (2010), a partir da necessidade de uma produção mais limpa social e ecologicamente -, que viria a nos exigir maior quantidade de trabalho, que poderia ser repartida - sob a condição de que fossem estabelecidos 
os meios necessários, notadamente em termos de formação - entre uma parte importante da população ativa, e de uma partilha mais equitativa do trabalho. Este seria um dos aspectos de uma reconversão ecológica.

Outro aspecto tem a ver com a RTT. Como lembra a autora, um relatório de 2014 da Comissão Especial da Assembleia Nacional a respeito dos impactos financeiros, econômicos, sociais e societários da RTT (Assemblée Nationale, 2014) apontou a medida como um dos instrumentos menos custosos e um dos principais meios de assegurar a igualdade profissional entre homens e mulheres. Seria, então, possível, em tese, repartir o volume de trabalho existente e suplementar de um modo diferente do que hoje é feito, o que poderia constituir um novo fluxo de recursos para os sistemas de proteção social.

Diante disso, Méda (2014) argumenta que o engajamento em uma reconversão ecológica constituiria igualmente uma oportunidade para modificar o trabalho. $\bigcirc$ objetivo principal não consistiria mais em ter a maior produção possível, a taxa de crescimento mais alta e que não se trata mais de ser o mais eficaz possível na produção (sob o risco de fazer com que o trabalho perca todo o seu sentido) e de realizar não ganhos de produtividade, mas ganhos de qualidade e de durabilidade, pondera a autora.

Seria essa uma ocasião especial, crítica, para que se revertessem os males atuais do trabalho - como sua intensificação, sua autonomia controlada, a falta de suporte da hierarquia, o aumento das restrições na busca de um aumento de seu ritmo. ${ }^{9}$ A oportunidade seria diminuir esses males graças a um processo de "desintensificação" do trabalho (Méda, 2014, 290).

\section{Considerações finais}

Observamos o panorama inquietante e desolador de uma recessão mundial, instalada a partir do epicentro de mercados financeiros mundializados desde 2008. Interconectadas, as economias nacionais vão, como numa imensa queda de dominós, deslizando para baixo, umas sobre as outras.

A retomada geral do crescimento não se poderia completar diante de tal lógica. Tidos como falhas regulatórias, os dumpings social, ambiental e fis-

9 Esses foram males colocados em evidência pela última onda de pesquisa Condições de Trabalho da Direção de Animação, da Pesquisa e dos Estudos Estatísticos (DARES na sigla em francês) e pela Pesquisa Europeia sobre as Condições de Trabalho. 
cal têm-se constituído como elementos típicos, próprios do funcionamento dos mercados mundiais desregulados. Foi a desregulamentação global que lhes franqueou o caminho e, hoje, a cobrança nos vem na forma de uma crise sem precedentes. A competitividade defendida por uma agenda (neo)liberalizante é impraticável, uma conta de soma negativa. Perdem as economias outrora líderes na industrialização - em crescimento, em empregos, qualidade de vida. Perdem os newcomers, com seu trabalho aviltado, descambando para a servidão e a escravidão, com seus abismos sociais e com seu ambiente deteriorado, que vai se perdendo irremediavelmente. Numa crescente espiral embalada pela crescente onda conservadora, o denominador comum entre ricos e pobres - e remediados - tem sido a degradação moral, a desumanização. E a perda da resiliência da biosfera.

Digamos que não haja um relance do crescimento global. As saídas que se nos colocam os tenentes do crescimento são pautadas por uma não demonstrada capacidade de geração de empregos. Os apelos da austeridade por sacrifícios em troca da retomada soam como chantagem social.

A retomada do debate da RTT, como nos tocou defender neste artigo, desde algumas de suas fontes históricas, coloca-se hoje como integrante de outra episteme. Uma que congregue saberes para a reconstrução de um sentido substantivo do econômico.

Por fim, precisamos dirigir algumas palavras a indagações pertinentes que sabemos ser suscitadas por este artigo.

Pensar sobre "como" transitar para formas de organização social capazes de um convívio mais harmônico entre semelhantes e considerando as limitações biofísicas não é tema que possa ser comportado nos limites deste artigo. Estamos conscientes do fervilhar de indagações sobre os modos pelos quais as transições entrevistas pelos autores que visitamos neste artigo devem ensejar. Da mesma forma, devem fluir ao longo da leitura, os mais legítimos questionamentos sobre quais seriam os destinos - ou efetivamente quais seriam as formas alternativas de organização da sociedade - e quais os caminhos para alcançá-las. Embora não seja este o objeto da reflexão proposta neste artigo, o reconhecimento da legitimidade e da relevância desses questionamentos nos coloca na posição de sugerir algumas pistas, dentro do debate contemporâneo, para a busca pelas respostas.

Existe uma safra relativamente recente de trabalhos acadêmicos que voltam seus olhares às transições ou transformações sociais ecologicamente comprometidas. Mencionaremos, abaixo apenas algumas delas, 
assumindo o risco de oferecer ao leitor uma mostra extremamente restrita deste campo florescente.

Perfilam-se, neste campo, de modo mais ou menos alinhadas, em termos de abordagens que se propõem interdisciplinares e que partem do diálogo entre Ciências Naturais e Sociais Aplicadas/Humanidades, contribuições como a de Acosta e Martinez (2009), a de Schor e White (2010) e Latouche (2018). Se o desenvolvimento sustentável não é denominador comum a essas obras, há uma interessante perspectiva compartilhada: não existe visão única sobre quais seriam as formas possíveis da organização social. Dito de outra forma, não há um destino comum. Bom sinal: para esses autores, a História perdura como processo aberto.

\section{Referências}

ACOSTA, A.; MARTINEZ, E. El buen vivir: una vía para el desarrollo. Quito: Abya-Yala, 2009.

AYRES, R. Sustainability Economics: where do we stand? Ecological Economics, (67): 281-310, 2008.

ASSEMBLÉE NATIONALE, Rapport Fait au nom de la Comission d'Enquête sur l'impact sociétal, social, économique et financier de la réduction progressive du temps de travail. Paris: France, 2014, no. 2436. http://www.assemblee-nationale.fr/14/rap-enq/r2436.asp consultado em $09 / 06 / 2020$

BANCO MUNDIAL. Where is the Wealth of the Nations? Measuring Capital for the Twenty First Century. Washington, DC: Banco Mundial, 2006.

BAUMAN, Z. Vida para consumo: a transformação das pessoas em mercadoria. Rio de Janeiro: Zahar, 2008.

BAUMOL, W. J.; BOWEN, W. G. On the performing arts: the anatomy of their economic problems. The American Economic Review, 55(1/2): 495-502, 1965.

BRYNJOLFSSON, E.; MCAFEE A. Race against the machine. Lexington, MA: Digital Frontier Press, 2011.

BRYNJOLFSSON, E.; MCAFEE, A. The second machine age. New York, NY: W. W. Norton \& Company, 2014.

DALY, H. E. The economics of the steady state. The American Economic Review, 64(2): 15-21, 1974.

DALY, H. E. Steady-state economics: With new essays. Island Press, US, 1991.

DARDOT, P.; LAVAL, C. A nova razão do mundo. São Paulo: Boitempo, 2016.

DAVIES, W. The New Neoliberalism. New Left Review, (101): 121-134, 2016.

FRACALANZA, P. S. Limites das abordagens microeconômicas da redução da jornada de trabalho. Revista de Economia, (34): 29-47, 2008. 
GADREY, J. Une économie post-croissance riche en emplois. Paris, Alternatives Économiques, (2): 66, 2010.

GADREY, J. Adieu à la croissance. Paris: Les Petits Matins- Alternatives Économiques. 3. ed. rév. 2015.

GEORGESCU-ROEGEN, N. The entropy law and the economic process. Cambridge, Mass.; London: Harvard University Press, c1971. xv, 457p.

GEORGESCU-ROEGEN, N. Energy and economic myths. Southern Economic Journal, 41(3): 347-381, 1975.

GORZ, A. Metamorfoses do Trabalho: crítica da razão econômica. São Paulo: Annablume, 2007 [1988].

GORZ, A. Écologica. Paris: Galilée, 2008. 158 p.

ILO. World Employment and Social Outlook: Trends. 2016. Disponível em: <http://ilo.org/global/research/global-reports/weso/2016/WCMS_443480/lang--en/index.htm>. Acesso em: 4 abr. 2020.

JACKSON, T. Prosperity without growth: economics for a finite planet. London, UK: Earthscan, 2009.

JANY-CATRICE, F.; MÉDA, D. Faut-il attendre la croissance? La Documentation Française, 2016.

JUDT, T. O mal ronda a terra. São Paulo: Objetiva Editora, 2011.

KEYNES, J. M. Economic Possibilities For Our Grandchildren. In: Essays in Persuasion. New York: W. W Nortan \& Co, 1963 [1930].

LAFARGUE, P. Le Droit à la Paresse. Paris: Librairie François Maspero, 1880 [1965]. Factor X. Eco-Efficiency in Industry and Science, Springer, UK, 2018.

LATOUCHE, S. The Path to Degrowth for a Sustainable Society. In: LEHMANN, H. (Ed) Factor X. Eco-Efficiency in Industry and Science, Springer, UK, 2018.

LIPOVETSKY, G. A felicidade paradoxal: ensaio sobre a sociedade de hiperconsumo. São Paulo: Companhia das Letras, 2007.

MARIS, B.; DOSTALER, G. Capitalisme et pulsion de mort. Paris: Albin Michel. 2009.

MARX, K. O capital. São Paulo: Boitempo Editorial, 1867 [2013].

MÉDA, D. La mystique de la croissance: comment s'en libérer. Flammarion, 2014.

MÉDA, D. Stratégies de croissance et environnement: quelle conciliation? Revue Française des Affaires Sociales, (1): 279-296, 2016.

PIKETTY, T. Capital in the Twenty-First Century. Cambridge (MA): Harvard University Press, 2013.

POLANYI, Karl. A grande transformação: as origens da nossa época. Tradução de Fanny Wrobel. 2. ed. Rio de Janeiro, RJ: Elsevier, 2012a. 342 p.

POLANYI, K. A subsistência do homem e ensaios correlatos. Rio de Janeiro: Contraponto, 1944 [2012b].

ROCKSTRÖM, J. et al. A safe operating space for humanity. Nature, 461(7.263): 472-475, 2009. 
RUSSELL, B. In Praise of Idleness. Harper's Magazine, 1932. Disponível em: <http://harpers. org/archive/1932/10/in-praise-of-idleness/>. Acesso em: 4 abr. 2020.

SCHOR, J.; WHITE, K. E. Plenitude: The new economics of true wealth. New York: Penguin Press, 2010

SKIDELSKY, R.; SKIDELSKY, E. How Much is Enough? New York: New Press, 2012.

STANDING, G. O precariado. Belo Horizonte: Autêntica, 2013.

STIGLITZ J.; SEN, A.; FITOUSSI J. P. Rapport sur la mesure des performances économiques et du progrès social, 2009.

TEULINGS C.; BALDWIN R. (Eds.). Secular Stagnation: Facts, Causes, and Cure, Londres, 2014.

VICTOR, P. A. Managing without growth: Slower by design, not disaster. Edward Elgar Publishing, 2008.

VIVERET, P. Préface à l'édition française. In: TIMOTHY, J. Prosperité sans croissance: la transition vers une économie durable. Bruxelles: Ed. De Boeck, 2009.

WILKINSON, R.; PICKETT, K. The Spirit Level. UK: Penguin, 2010.

WJUNISKI, B. S.; FERNANDEZ, R. G. Karl Polanyi, Athens and us: the contemporary significance of Polanyi's thought. Revista de Economia Politica, 30(3): 420-437, 2010.

\section{Sobre os autores}

Paulo Sérgio Fracalanza - fracalan@unicamp.br

Instituto de Economia, Universidade Estadual de Campinas, Campinas, São Paulo, Brasil.

ORCID: https://orcid.org/0000-0002-8395-981X.

Mariana Rêis Maria - marireis_maria@hotmail.com

Instituto de Economia, Universidade Estadual de Campinas, Campinas, São Paulo, Brasil.

ORCID: https://orcid.org/0000-0002-0036-3667.

Rosana Icassatti Corazza - rcorazza@unicamp.br

Departamento de Política Científica e Tecnológica, Instituto de Geociências, Universidade Estadual de Campinas, Campinas, São Paulo, Brasil.

ORCID: https://orcid.org/0000-0003-4658-2889.

Os autores agradecem à(ao) parecerista ad hoc da Revista Nova Economia, pela leitura cuidadosa do manuscrito e por suas observações pertinentes que, seguramente, tornaram a leitura deste artigo mais fluida e seus argumentos mais claros.

\section{Sobre $o$ artigo}

Recebido em 13 de agosto de 2018. Aprovado em 06 de março de 2019. 